\title{
KONSUMSI MENUJU KONSTRUKSI MASYARAKAT KONSUMTIF
}

\author{
M. Chairul Basrun Umanailo, Mansyur Nawawi, Sukainap Pulhehe
}

\author{
Program Studi Sosiologi, Universitas Iqra, Buru, Indonesia
}

chairulbasrun@gmail.com

\begin{abstract}
This article aims to analyze public consumption actions as a practice model that will create a new model in understanding consumption patterns to become consumptive. The pattern of public consumption in its development has shifted due to the availability of modern technology and facilities. The approach used in this paper is library research, with data analysis techniques in the form of content analysis with the aim of obtaining valid inferences and can be re-examined based on the context. the presence of technology as a representation of facilities in meeting needs is able to encourage the creation of social change, such as the spread of consumerism culture, changes in dress and lifestyle modes where these conditions are institutionalized in the cultural structure of society so that consumption of goods is not based solely on the logic of needs, but will include substantial someone's emotions. The situation systematically shifts traditional values and leads to global behavior. Consumption towards the construction of consumptive society is a conceptual and historical illustration for all of us to further understand the shifting consumption into consumptive practices.
\end{abstract}

Keywords: consumerism, construction, society, consumptive

\begin{abstract}
Abstrak
Artikel ini bertujuan menganalisis tindakan konsumsi masyarakat sebagai model praktik yang akan menciptakan model baru dalam pemahaman pola konsumsi menjadi konsumtif. Pola konsumsi masyarakat dalam perkembangannya mengalami pergeseran akibat ketersediaan teknologi dan fasilitas modern. Pendekatan yang digunakan dalam penulisan ini adalah studi kepustakaan, dengan teknik analisis data berupa content analysis dengan tujuan untuk mendapatkan inferensi yang valid dan dapat diteliti ulang berdasarkan konteksnya. kehadiran teknologi sebagai representasi fasilitas dalam pemenuhan kebutuhan mampu mendorong terciptanya perubahan sosial, seperti merebaknya budaya konsumerisme, perubahan mode berpakaian dan gaya hidup di mana kondisi ini terlembaga dalam struktur budaya masyarakat
\end{abstract}


sehingga mengkonsumsi barang tidak hanya didasarkan pada logika kebutuhan semata, akan tetapi akan mencakup subtansial emosi seseorang. Situasi tersebut secara sistematis menggeser nilai-nilai tradisi dan mengarah pada perilaku global. Konsumsi menuju konstruksi masyarakat konsumtif menjadi sebuah ilustrasi konseptual dan historis bagi kita semua untuk lebih jauh memahami konsumsi yang telah bergeser menjadi praktik konsumtif.

Kata Kunci: konsumerisme, konstruksi, masyarakat, konsumtif

\section{PENDAHULUAN}

Masyarakat modern adalah masyarakat konsumtif, masyarakat yang terus menerus berkonsumsi. Namun, konsumsi yang dilakukan bukan lagi hanya sekedar kegiatan yang berasal dari produksi. Konsumsi tidak lagi sekedar kegiatan pemenuhan kebutuhankebutuhan dasar dan fungsional manusia. Konsumsi telah menjadi budaya, dan sistem masyarakat pun telah berubah, dan yang ada kini adalah masyarakat konsumen, yang mana kebijakan dan aturan-aturan sosial masyarakat sangat dipengaruhi oleh kebijakan pasar.

Awal terbangunnya konsumerisme ketika orang mulai mengagumi keberadaan teori konsumsi, terjadi pergeseran makna pada tataran teoritis, individu menyadari bahwa hidup bukan sekedar menjangkau atau mencari sumber ekonomi namun juga bagaimana mengelola sumber-sumber itu agar bertahan lama, bahkan mungkin selamanya untuk kesejahteraan individu. Perubahan cara produksi diikuti dengan kekacauan sosial skala besar yang akhirnya menyebabkan tumbangnya cara hidup tradisional yang berbasis pada produksi pertanian (Ritzer, 2012).

Ada tendensi evolusi dalam perjalanan konsumerisme sebagai penjelmaan nilai lebih dari suatu komoditas akibat bergesernya fungsi barang. Bagi kita semua, keberadaan konsumerisme bukan tergantung pada waktu, melainkan kesempatan dalam kepemilikan capital dan tersedianya sumber-sumber ekonomi yang mengarah pada terjadinya hukum dominasi, bukan hukum permintaan (Baudrillard, 2013). Mengkaji lebih jauh terjadinya migrasi besar-besaran ke pusat-pusat kota yang baru terbentuk, kelas-kelas social yang dulunya muncul sebagai budak kini ditransformasikan menjadi buruh yang diupah (Ritzer, 2012).

Sulistyaningtyas (2017) dalam kajiannya mengenai Consumerism Discourse and Ideological Calling in Commercial Website of San Diego Hills Memorial Parks and Funeral Homes menyatakan bahwa mereka didorong untuk mengidentifikasi dirinya sebagai bagian dari kelas sosial tertentu. Setiap pemakaman ditawarkan sesuai dengan gaya dan kelas sosial calon pelanggannya. Wacana ini mendorong masyarakat, khususnya pelanggan, untuk mengonsumsi tanda dan makna yang dibangun melalui wacana tersebut. Sementara itu, Jati (2015) dalam penelitiannya tentang Less Cash Society menyajikan hasil temuan berupa pola konsumsi kelas menengah Indonesia mengalami transisi dari pemenuhan 
kebutuhan hidup menjadi kebutuhan simbolis. Adanya pengejaran terhadap identitas dan gaya hidup itulah yang menjadikan konsumsi kelas menengah Indonesia kini lebih bersifat sekunder. Selain itu, Saputra (2017) menyajikan gambaran mengenai globlisasi yang dianggap sebagai penyebab budaya luar dapat masuk dan dari budaya luarlah yang menyebabkan bergesernya nilai seni menjadi ukuran privasi dan ekonomi dalam struktur masyarakat.

Memahami hasil penelitian yang sebelumnya telah dilakukan, maka kajian ini memfokuskan pada kajian konteks dan pemikiran mengenai konsumsi itu sendiri. Pemaknaan terhadap konsumsi dielaborasi untuk mendapatkan gambaran kontekstual secara teoritik maupun praktik. Pada kajian ini, peneliti menggunakan pendekatan berupa studi kepustakaan. Studi kepustakaan merupakan suatu studi yang digunakan dalam mengumpulkan informasi dan data dengan bantuan berbagai macam material yang ada di perpustakaan maupun internet seperti dokumen, buku, jurnal, majalah, kisah-kisah sejarah (Mirzaqon, 2018:3). Sementara itu, menurut ahli, studi kepustakaan merupakan kajian teoritis, referensi serta literatur ilmiah lainnya yang berkaitan dengan budaya, nilai dan norma yang berkembang pada situasi sosial yang diteliti.

Teknik analisis data yang digunakan dalam penelitian ini adalah metode analisis isi (content analysis). Analisis ini digunakan untuk mendapatkan inferensi yang valid dan dapat diteliti ulang berdasarkan konteksnya (Kripendoff, 1993). Dalam analisis ini akan dilakukan proses memilih, membandingkan, menggabungkan dan memilah berbagai pengertian hingga ditemukan yang relevan (Mirzaqon, 2018:4).

\section{HASIL DAN PEMBAHASAN}

\section{Konteks Konsumsi Dari Cara Pandang Sosiolog}

Mengikuti urutan sejarah sistem industrial silsilah/asal usul konsumsi: (1) tatanan produksi menghasilkan mesin/ kekuatan produktif; (2) ia menghasilkan modal/kekuatan produktif yang masuk akal; (3) ia menghasilkan tenaga kerja bergaji, kekuatan produktif yang abstrak, tersistimatisir, yang secara mendasar berbeda dengan pekerjaan nyata dan pekerjaan tradisional; dan (4) terakhir ia melahirkan kebutuhan-kebutuhan, sistem kebutuhan, permintaan/kekuatan produktif sebagai kumpulan yang dirasionalkan, disatukan, diawasi (Umanailo, 2018). Semua itu dibuat sebagai unsur sistem, dan bukan hubungan sebagai individu denganh objek, menunjukan bahwa hubungan manusia dengan objek-objek hubungan manusia dengan dirinya sendiri dipalsukan, dikelabui, dimanipulasi.

Hampir semua filsuf sosial yang menulis tentang kebangkitan konsumsi sebagai gejala individual yang mengancam tatanan sosial. Weber (1904) memandang konsumsi sebagai ancaman bagi etika Protestan kapitalis. Durkheim (1964) menyamakan konsumsi dengan anomi pengancam masyarakat yang bisa diperbaiki dengan interelasiinterrelasi fungsional dalam pembagianpembagian kerja yang ditemukan dalam produksi. Bagi ekonom, inilah "Utilitas" keinginan memperoleh satu kebaikan tertentu yang khusus di akhir konsumsi. Maka kebutuhan telah terpenuhi oleh 
barang-barang yang tersedia, hobi yang diarahkan oleh potongan produk yang tersedia di pasar: inilah hakikat permintaan yang sanggup dipenuhi. Konsumsi adalah sistem yang dianggap menjalankan urutan tanda-tanda dan penyamaan serta penyatuan kelompok. Jadi konsumsi itu sekaligus sebuah moral (sebuah sistem nilai ideologi) dan sistem berkomunikasi serta struktur pertukaran.

Menurut hipotesa ini, dan juga paradoks mengenai hal itu munculnya konsumsi didefinisikan sebagai kenikmatan yang eksklusif. Sebagai logika sistem, sistem konsumsi didirikan di atas dasar pengingkaran kenikmatan. Di sana kenikmatan tidak lagi muncul sama sekali sebagai tujuan rasional, tetapi sebagai rasionalisasi individu pada suatu proses yang bertujuan lain (Umanailo, 2018). Kenikmatan akan memberi batasan konsumsi bagi dirinya, otonom, dan akhir konsumsi Konsumsi, menurut Piliang, dapat dimaknai sebagai sebuah proses objektifikasi, yaitu proses eksternalisasi atau internalisasi diri lewat objek-objek sebagai medianya. Maksudnya, bagaimana kita memahami dan mengkonseptualisasikan diri maupun realitas di sekitar kita melalui objek-objek material. Di sini terjadi proses menciptakan nilai-nilai melalui objek-objek dan kemudian memberikan pengakuan serta penginternalisasian nilai-nilai tersebut (Piliang, 2004).

Marxjuga membahaskonsumsi secara langsung dan rinci dalam karya-karyanya. Sebagian besar pembahasan itu tentang membangun hubungan dialektis tiga rangkap antara konsumsi dan produksi. Pertama, konsumsi selalu merupakan produksi, dan produksi selalu merupakan konsumsi artinya dalam memproduksi objek selalu ada konsumsi tenaga bahan dan tenaga manusia; sedangkan dalam mengonsumsi objek, ada aspek tertentu dari konsumen yang diproduksi. Kedua, produksi dan konsumsi bersifat interdependen. Produksi menciptakan objek yang diperlukan untuk konsumsi dan konsumsi menciptakan motivasi untuk produksi. Ketiga, produksi dan konsumsi saling menciptakan. Produksi selesai melalui konsumsi yang menciptakan kebutuhan akan produksi lebih lanjut. Sebaliknya konsumsi hanya tercipta sebagai salah satu realitas materi melalui produksi karena kebutuhan yang mendorong konsumsi hanya menjadi konkret dalam hubungannya dengan objek-objek tertentu yang telah di produksi. Menurut Gervasi; "pilihanpilihan tidak dibuat secara kebetulan, tetapi terkontrol secara sosial, dan mengambarkan model budaya di tengah budaya yang mereka buat." Orang tidak menghasilkan juga tidak mengkonsumsi benda apa saja: mereka harus memiliki beberapa arti menurut pandangan sistim nilai. Tujuan ekonomi bukanlah memaksimalkan produksi untuk individu, tapi maksimalisasi produksi yang berhubungan dengan sistem nilai masyarakat (Umanailo, 2018).

Kerangka pikir yang membedakan antara nilai guna yang sesunguhnya (true use values) dengan ciri-ciri palsu objek yang difetisisasikan dan dialienasikan. Kerangka pikir dan pembedaan ini mendefenisikan pendekatan Marx bahwa konsumsi atas sesuatu yang secara fungsional dianggap berguna akan dilegitimasikan sebagai kebutuhan, sedangkan semua konsumsi lain yang terkait dengan kemewahan dianggap sebagai kemerosotan moral. 
Penghasilan, belanja prestise, membentuk lingkaran setan dan kebingungan, lingkaran kejam konsumsi, yang didasarkan atas kegairahan kebutuhan yang disebut "psikologis", yang berbeda-beda kebutuhan fisiologis dalam apa yang mereka dasarkan pada "penghasilanyang tergantung pada orang yang berkuasa" dan kebebasan memilih, akhirnya menjadi manipulable mercia. Untuk menerima bahwa kebebasan dan kedaulatan konsumen hanyalah perbuatan mistifikasi (memperdaya orang banyak).

Horkheimer dan

Adorno menggambarkan industri kebudayaan diorganisasi dengan berpusat pada model-model produksi massa ala Fordisme. Fordisme tidak hanya menghasilkan barang konsumen yang homogen, tapi juga standarisasi dan komodifikasi produk-produk kebudayaan buatan pabrik. Marcuse menyatakan bahwa orang mengenali dirinya dari komoditas - kontrol sosial ditentukan dari kebutuhan-kebutuhan baru yang ditimbulkannya. Marcuse mendiagnosa persoalan pada masyarakat konsumen adalah kenikmatan yang tidak cukup. Kebudayaan konsumen dalam kapitalisme kontemporer bukanlah tempat bagi hedonisme yang tak terkendali, melainkan tempat bagi kesenangan-kesenangan yang terkendali secara birokratis dan dirasionalisasi. Garis batas "palsu", kesenangan pada televisi atau kesenangan memiliki villa adalah nyata sebagai "kebebasan yang sebenarnya", tak seorangpun menghidupkan sebagai alienasi.

Analisis Simmel tentang peranan uang dalam modernitas adalah bahwa pertumbuhan dan reifikasi kebudayaan objektif juga bermanfaat karena menyediakan lebih banyak peluang bagi individu untuk mengekspresikan kebebasan dan individualitas. Bukannya menggunakan macam-macam komoditas yang sangat banyak ini, malah seringkali kitalah yang dimanfaatkan oleh komoditas-komoditas itu.

Veblen mengutarakan bahwa kelas atas menggunakan konsumsi berlebihan untuk membedakan diri dari kelas-kelas di bawahnya dalam hierakhi sosial, sementara kelas-kelas bawah berupaya (dan biasanya gagal) meniru tingkatan di atas mereka. Dorongan untuk meniru ini memicu efek "mengalir ke bawah", yaitu kelas atas menjadi penentu bagi semua konsumsi yang terjadi dibawahnya. Praktik-praktik konsumsi yang dilakukan leisure class - kelas yang lebih banyak memiliki waktu luang ketimbang bekerja - dicelanya karena dia menggunakan kecakapan kerja dan produksi. Jadi dengan mengkonsumsi objek, sesungguhnya kita sedang mengonsumsi bermacam-macam makna yang terkait dengan kelas.

De Certeau menjelaskan pula bahwa konsumen bukan hanya dikontrol oleh manipulasi pemasaran seperti yang ingin diyakinkan kaum Marxis, neoMarxis, dan lain-lain, tetapi konsumen sendiri juga menjadi manipulator aktif. Bukannya patuh menggunakan jasa dan barang konsumen sesuai yang diharapkan, konsumen menggunakan jasa dan barang itu dengan cara sendiri sesuai kebutuhan dan kepentingannya.

\section{OBJEK KONSUMSI}

Adam Smith mendekati studi objek-objek konsumsi dengan konsep komoditas. Bagi Smith dan Marx, 
komoditas terutama dipandang sebagai bagaian dari proses produksi. Jean Baudrillard menulis dalam The System of Objects bahwa untuk menjadi objek konsumsi, terlebih dahulu sebuah objek harus menjadi tanda. Jadi memahami konsumsi kita perlu mampu membaca barang konsumen sebagai serangkaian tanda sama dengan bahasa yang memerlukan penafsiran.

Baudrillard menerangkan bahwa sebuah objek mulai menjadi objek konsumsi bila tidak lagi ditentukan oleh hal-hal berikut seperti tempat objek di dalam sebuah siklus produksi, kegunaan dari fungsional objek dan juga makna simbolis objek. Objek konsumen adalah pesan, barang konsumen adalah piranti lunak dan piranti keras dalam sebuah sistem informasi yang urusan utamanya ialah memantau kinerjanya sendiri. Metafora konsumsi sebagai manipulasi tanda lebih berguna untuk membedakan antara konsumsi dan bahasa daripada untuk menyamakannya. Barang konsumen bekerja serasi menciptakan satu keseluruhan bermakna dan konsisten. Membeli sepasang sepatu baru menciptakan ketidakserasian dengan setelan yang lama; jadi, orang harus membeli rok baru, blus baru, dan dompet baru agar semua objek konsumen bisa dipadupadankan.

\section{SUBJEK KONSUMSI}

Gabriel dan Lang menunjukan tipe konsumen sangat bermacam-macam; korban, pemilih, komunikator, pencobacoba, pencari identitas, hedonis, artis, pemberontak, aktivis, atau warga. Daftar ini memang tidak lengkap, tetapi berhasil menyampaikan fakta bahwa ada keanekaragaman di kalangan konsumen.
Habitus adalah sistem struktur-struktur penstruktur yang bergabung menjadi keseluruhan teratur, yang diciptakan guna menanggapi kondisi-kondisi objektif dan dipelajari melalui sosialisasi. Ciri terpenting habitus ialah habitus bukan mengontrol aktor, tetapi dapat dikalahkan melalui refleksivitas. Dalam Distinction, Bourdieu menghubungkan habitus dengan selera. Dengan konsep habitus, Bourdieu sanggup menghubungkan mikropraktik-mikropraktik tampak voluntaristis yang biasa diasosiasikan dengan selera mikro struktur kelas-kelas kapitalis. Dalam pandangan ini, konsumsi bisa dianggap sebagai pilihan-pilihan gaya hidup strategis sadar yang dibuat konsumen dengan dilatarbelakangi selera-selera tak sadar yang menjadi ciri suatu habitus kelas.

Konsumsi dibayangkan sebagai sebuah ranah tempat niat dan tujuan aktor-aktor individu ditopang dan ditransformasi melalui manipulasimanipulasi eksperimental pada sitem objek-objek. Bauman berargumen bahwa pengalaman kebebasan yang dikaitkan dengan konsumsi akan menghindari dua masalah ini. Pertama, karena wilayah konsumsi modern lebih berpusat pada gaya hidup daripada barang. Kedua, mereka yang melakukan belanja gaya hidup dapat bereksperimen dengan bentuk-bentuk komunitas yang bisa dimasuki dan ditinggalkan tanpa harus mengompromi kebebasan individu mereka.

\section{TEMPAT-TEMPAT KONSUMSI}

Pendekatan Benjamin pada konsumsi berpusat pada peranan yang dimainkan perubahan teknologi. Munculnya 
foto dan ancaman yang dibawanya terhadap lukisan. Studi sejarah teori sosial dan konsumsi Rosalind Williams dapat dianggap menghubungkan karya Benjamin dengan konsep anomi Durkheim. Williams menekankan peranan yang dimainkan tempat-temapt khusus ini (pekan raya dunia, toko serba ada) dalam membangkitkan dan membakar hasrat konsumen, juga dalam menumbuhkan masyarakat konsumen. Eksposisi dunia dan toko-toko serba ada, dalam periode ini merupakan dunia-dunia impian yang dipilih untuk membangkitkan minat konsumen terhadap konsumsi, menghibur konsumen, menyediakan tempat, barang, dan jasa yang mampu memenuhi kebutuhan imajinasi mereka. Tempattempat ini memikat dan menggoda konsumen dengan fantasi.

Upaya lebih kontemporer ditawarkan Ritzer untuk menyeimbangkan minatminat tradisional pada konsumen, objekobjek konsumen, dan proses konsumsi, dengan lebih banyak mencurahkan perhatian pada tempat-tempat konsumsi. John Urry menyebut tempat-tempat ini "tempat konsumsi atau tempat untuk konsumsi". Konteks yang di dalamnya barang dan jasa diperbandingkan, dievaluasi, dibeli dan dipergunakan. Di satu sisi, tempat-tempat ini dipaksa untuk melakukan rasionalisasi dan birokratisasi, khususnya jika tempat-tempat itu berusaha melayani klien dan pelanggan dalam jumlah besar serta beroperasi di sejumlah lingkungan geografi berbeda.

\section{PROSES KONSUMSI}

Studi menarik mengenai proses konsumsi ialah A Theory of Shopping karya Daniel Miller, tiga tahap menuju konsumsi. Tahap pertama adalah visi pengalaman berbelanja murni, biasa disebut "real shopping". Dalam visi ini, konsumen hedonistis secara tak bertanggung jawab menjarahi dan meludeskan sumber daya, berkolaborasi dengan kapitalisme dalam merusak diri sendiri dan bumi. Tahap kedua, konsumen menerapkan strategi dan ketrampilan menghemat. Dalam praktik, biasanya shopping dijelaskan sebagai kesempatan untuk menghemat uang, bukan untuk menghabiskannya. Tahap ketiga, proses-proses konsumsi dikaitkan dengan hubungan-hubungan sosial nyata dan ideal yang membentuk dunia pembelanja. Dalam tahap ini khususnya, konsumen tipikal yang terkait dengan salah satu gender membeli merek atau rasa tertentu sehubungan dengan pemahamannya tentang bukan hanya soal kebutuhan semata-mata, melainkan pemikirannya tentang apa yang akan meningkatkan kualitasnya sebagai individu.

Miller menyimpulkan bahwa "tujuan primer dibalik shopping bukanlah untuk membeli barang-barang yang dibutuhkan melainkan usaha untuk berhubungan dengan subjek-subjek yang menghendaki barang-barang ini". Ritzer mengidentifikasikan perubahan yakni, pertama, daripada harus pergi ke banyak lokasi yang berbeda, tempattempat seperti pusat perbelanjaan (shopping mall) dan pusat belanja besar (mega mall) (juga toko pangan serba ada dan toko serba ada raksasa) telah memungkinkan adanya one stop shopping belanja apa saja di satu tempat. Banyak katedral konsumsi (seperti megamall, Disney World, kapal pesiar, Las Vegas dengan kasino-hotelnya) dengan segenap 
keistimewaannya telah menjadi tempat tujuan dan orang-orang mendatanginya untuk mengkonsumsi tempat-tempat itu seperti halnya mereka mengonsumsi barang dan jasa yang ditawarkan di sana. Ketiga, bukannya menyuruh pelayan melayani konsumen, kini banyak konsumsi yang mengharuskan konsumen melakukan swalayan, tanpa dibayar. Pada akhirnya katedral-katedral konsumsi mengubah relasi sosial sedemikian rupa sehingga konsumen lebih banyak berinteraksi dengan tempat dan yang ditawarkan tempat itu, bukan dengan orang yang bekerja di sana atau dengan sesama konsumen.

Konsumsi adalah sebuah perilaku aktif dan kolektif, ia merupakan sebuah paksaan, sebuah moral, konsumsi adalah sebuah institusi. Ia adalah keseluruhan nilai, istilah ini berimplikasi sebagai fungsi integrasi kelompok dan integrasi control social (Umanailo, 2018). Masyarakat konsumsi (Baudrillard, 2013: 92) juga merupakan masyarakat pembelajaran konsumsi, pelatihan sosial dalam konsumsi artinya sebuah cara baru dan spesifik bersosialisasi dalam hubungannya dengan munculnya kekuatan-kekuatan produktif baru dan restrukturisasi monopolistik sistem ekonomi pada produktivitas yang tinggi.

Semua ideologi konsumsi ingin meyakinkan kita bahwa kita telah memasuki era baru dan sebuah revolusi kemanusiaan yang menentukan, yang memisahkan zaman yang menyedihkan dan heroik terhadap produksi dengan zaman euforia konsumsi, dimana ia telah mengembalikan hak pada manusia dan pada keinginannya (Umanailo, 2018). Konsumsi tampak berlawanan dengan ideologi nyata, sebagai suatu dimensi paksaan yang: (1) didominasi oleh paksaan arti, pada tingkat analisis struktural; (2) didominasi oleh paksaan produksi dalam analisis strategis (sosioekonomi-politik).

\section{KESIMPULAN}

Analisis terhadap konten konsumsi dapat dielaborasi dengan melihat dari berbagai perspektif yang dikemukakan oleh para ahli, subtansi yang bisa dikemukakan bahwa konsumsi merupakan suatu gaya berpikir dan gaya bertindak oleh manusia dalam memaknai kebutuhan serta penyesuaian terhadap lingkungan hidup disekitar mereka. Masalah yang kemudian muncul setelah terjadinya artikulasi terhadap makna konsumsi itu sendiri merupakan konstruksi ideologi serta praktik dari masing-masing individu maupun kelompok masyarakat. Skema konsumtif pada masyarakat modern lebih didominasi oleh ketersediaan teknologi dan pergeseran pola pikir masyarakat terhadap pemenuhan kebutuhan hidup, sehingga teknologi menjadi pintu masuk untuk bergesernya masyarakat dari tradisonal ke modern dan pada akhirnya menuju pada masyarakat konsumtif.

\section{SARAN}

Upaya untuk menciptakan masyarakat yang tidak konsumtif bisa dimulai dengan menjelaskan dampak serta akibat dari sebuah praktik konsumsi yang konsumtif dengan harapan akan mampu membangun kesadaran individual untuk mengurangi bahkan menghindari tindakan yang menuju pada tindakan konsumtif itu sendiri. 
DAFTAR PUSTAKA

Agger, Ben. 2005. Teori Sosial Kritis, Kritik, Penerapan dan Implikasinya. Diterjemahkan oleh Nurhadi. Yogyakarta: Kreasi Wacana.

Baudrillard, J. P. 1987. The Ecstacy of Communication. New York: Semio(text).

Baudrillard, J. P. 2013. Masyarakat Konsumsi. Yogyakarta: Kreasi Wacana.

Feathersone, Mike. 1992. Consumer Culture and Posmodernism. London: Sage Publications.

Ritzer, George and Barry Smart. 2011. Handbook Teori Sosial. Jakarta: Nusamedia.

Jati, Wasisto Raharjo. 2015. Less Cash Society: Menakar Mode Konsumerisme Baru Kelas Menengah Indonesia. Jurnal Sosioteknologi, 14(2).

Mirzaqon, T. 2018. Studi Kepustakaan Mengenai Landasan Teori Dan Praktik Konseling Expressive Writing. Jurnal BK Unesa, 8(1).
Piliang, Yasraf Amir. 2004. Dunia yang Dilipat: Tamasya Melampaui BatasBatas Kebudayaan. Bandung: Jalasutra.

Saputra, Anggriawan Dwi. 2017. Masyarakat Konsumsi (Studi Deskriptif Gejala Konsumerisme Jasa Tato Pada Masyarakat Kota Surabaya). Paradigma, 05(03).

Stearns, Peter N. 2003. Consumerism in World History: The Global Transformation of Desire. New York: Routledge.

Subandi, Ibrahim Idi. 2005. Lifestyle Ecstasy, Kebudayaan Pop dalam Masyarakat Komoditas Indonesia. Yogyakarta: Jalasutra.

Sulistyaningtyas, Tri. dan Jejen Jaelani. 2017. Consumerism Discourse and Ideological Calling in Commercial Website of San Diego Hills Memorial Parks and Funeral Homes. Jurnal Sosioteknologi, 16(1). 